\title{
Early Detection of Restenosis After Successful Percutaneous Transluminal Coronary Angioplasty by Exercise-Redistribution Thallium Scintigraphy
}

\author{
WILLIAM WIJNS, MD, PATRICK W. SERRUYS, MD, JOHAN H.C. REIBER, PhD, \\ PIM J. de FEYTER, MD, MARCEL van den BRAND, MD, MAARTEN L. SIMOONS, MD, \\ and PAUL G. HUGENHOLTZ, MD, With the statistical assistance of JAN G.P. TIJSSEN
}

\begin{abstract}
The value of exercise testing and thallium scintigraphy in predicting recurrence of angina pectoris and restenosis after a primary successful transluminal coronary angioplasty (PTCA) was prospectively evaluated. In 89 patients, a svmptom-limited exercise electrocardiogram (EC $\mathbf{i}$ ) and thallium scintigraphy were performed 4 weeks after they had undergone successful PTCA. Thereafter, the patients were followed for $6.4 \pm 2.5$ months (mean \pm standard deviation) or until recurrence of angina. They all underwent a repeat coronary anglography at 6 months or earlier if symptoms recurred. PTCA was considered successful if the patients had no symptoms and if the stenosis was reduced to less than $50 \%$ of the luminal diameter. Restenosis was de-
\end{abstract}

fined as an increase of the stenosis to more than $50 \%$ luminal diameter. The ability of the thallium scintigram (presence of a reversible defect) to predict recurrence of angina was $66 \%$, vs $38 \%$ for the exercise ECG (ST-segment depression or angina at peak workload). Restenosis was predicted in $74 \%$ of patients by thallium scintigraphy, but only in $50 \%$ of patients by the exercise ECG. Thus, thallium scintigraphy was highly predictive but the exercise ECG was not $(p<0.005)$. These results suggest that restenosis had occurred to some extent already at 4 weeks after the PTCA in most patients in whom it was going to occur.

(Am J Cardiol 1985;55:357-361)
Restenosis after primary successful percutaneous transluminal coronary angioplasty (PTCA) occurs in 19 to $36 \%$ of patients within the first 6 months after the procedure. ${ }^{1-5}$ This restcnosis may manifest itself by changes in the patient's clinical status and may be detected by noninvasive diagnostic tests or by coronary angiography. Scholl ${ }^{2}$ and Hirzel ${ }^{6}$ and their co-workers showed that an abnormal response on the exercise electrocardiogram (ECG) and a myocardial perfusion defect on the thallium scintigram is associated with angiographically documented restenosis of the dilated vessel or is a sign of the presence of additional disease. The present study was performed to determine the value of early noninvasive testing in the prediction of restenosis and recurrence of symptoms. The study pa-

From the Thoraxcenter, Erasmus University and University Hospital Dijkzigt, Rotterdam, The Netherlands. Manuscript received June 27, 1984; revised manuscript received October 15, 1984, accepted October 16, 1984.

Address for reprints: Patrick W. Serruys, MD, Catheterization Laboratory, Thoraxcenter, Erasmus University, P.O. Box 1738, 3000 DR Rotterdam, The Netherlands. tients had undergone technically successful PTCA, which resulted in a "complete" anatomic correction. They were all free of angina pectoris up to the time of excrcise elcctrocardiography and thallium scintigraphy, which were performed a median of 4 weeks after PTCA. Follow-up data regarding subsequent recurrence of symptoms and repeat coronary angiography a median of 6 months after the procedure were compared in a prospective manner with the noninvasive test results obtained at 4 weeks.

\section{Methods}

Between September 1980 and September 1983, 296 consecutive first PTCA procedures for stable or unstable angina pectoris were attempted at the Thoraxcenter; 221 were primary successes. The 162 paticnts from our own institution were asked to cooperate with a follow-up protocol, which included an exercise electrocardiogram and thallium scintigram 4 to 6 weeks after the procedure, a visit to the outpatient clinic at 2-month intervals and a repeat angiogram at 6 to 8 months. The 59 patients referred from institutions in other cities were excluded. One hundred twenty patients met the inclusion criteria for the present study: "complete" anatomic correction, 
TABLE I Characteristics of the Angioplasty Procedure

\begin{tabular}{clccc}
\hline & & $\begin{array}{c}\text { Group 1 } \\
\text { Restenosis* } \\
(n=35)\end{array}$ & $\begin{array}{c}\text { Group 2 } \\
\text { Long-Term } \\
\text { Success } \\
(n=54)\end{array}$ \\
\hline $\begin{array}{c}\text { Dilated } \\
\text { vessel }\end{array}$ & LAD & 25 & & \\
(n=93) & RCA & 6 & & 34 \\
$\%$ diameter & Bypass & 5 & & 3 \\
stenosis & Post & $66 \pm 15$ & NS & $62 \pm 11$ \\
& Late & $62 \pm 12$ & NS & $31 \pm 13$ \\
Pressure & Before & $0.64 \pm 0.16(33)$ & NS & $0.61 \pm 0.13(55)$ \\
gradient & After & $0.19 \pm 0.11(35)$ & NS & $0.16 \pm 0.10(55)$ \\
\hline
\end{tabular}

The translesional pressure gradient is normalized for the mean aortic pressure; numbers under parentheses refer to the number of available measurements. * Stenosis more than $50 \%$ in luminal diameter at repeat angiography.

LAD = left anterior descending coronary artery; $L C X=$ left circumflex coronary artery; NS = not significant; RCA = right coronary artery.

i.e., no significant residual coronary obstructions after PTCA; absence of angina until the time of exercise testing; and ability to complete the exercise test. Thirty-one patients refused to undergo repeat coronary angiography. This report is thus based on the prospective evaluations of 89 patients, 74 men and 15 women. A single stenosis was dilated in 85 patients and 2 stenoses were dilated in 4 patients. The dilated vessel was the left anterior descending artery in 59 patients, the left circumflex in 9 , the right coronary artery in 24 and the distal anastomotic site of a saphenous vein bypass graft on the left anterior descending coronary artery in 1 patient. PTCA was performed according to the technique of Gruentzig, ${ }^{1}$ with Schneider equipment through a femoral route. Details regarding the procedure used in our laboratory were described previously ${ }^{7,8}$ The PTCA procedure was considered successful when the residual stenosis was less than $50 \%$ in diameter with a good run off and filling of the distal vessel at angiography. In the 91 stenoses with satisfactory recordings, the residual pressure gradient (normalized for the mean aortic pressure) was less than 0.20 in 63 cases and less than 0.40 in 25 cases.

In an attempt to reduce the restenosis rate, $, 3,5$ all patients received nifedipine, $10 \mathrm{mg}$ every 2 hours for the first 8 hours after the procedure and received maintenance therapy on salicylic acid, $500 \mathrm{mg} /$ day, and nifedipine, $10 \mathrm{mg} 3$ to 6 times daily, until repeat angiography was performed. Beta-blocking agents were stopped unless the patient had hypertension. Repeat angiography was performed $7.0 \pm 2.3$ months (mean \pm standard deviation) after PTCA in the patients who remained asymptomatic and $4.9 \pm 2.3$ months after PTCA in patients who had recurrent angina during follow-up. Coronary angiography was performed in multiple views (including hemiaxial views for the left coronary artery) and were interpreted visually without knowledge of the initial noninvasive test results. The clinical definition of restenosis was an increase of the diameter stenosis of the dilated lesion above the $50 \%$ level. In addition, quantitative analysis of the dilated stenosis was obtained in the same angiographic projection for each angiogram by means of our computer-based coronary angiographic analysis system..$^{9}$ Based on these accurate and more objective measurements of stenosis severity, ${ }^{10}$ the definition of restenosis used by the National Heart, Lung, and Blood Institute (NHLBI) registry ${ }^{4}$ was applied as well, i.e., an increase in stenosis of at least $30 \%$ from the immediate post-PTCA result or the loss of at least half the initial gain in diameter.

The exercise studies were performed $4.7 \pm 1.9$ weeks after PTCA. The subjects performed a symptom-limited exercise
TABLE II Exercise Test Results and Recurrence of Symptoms During Follow-Up

\begin{tabular}{lccc}
\hline & $\begin{array}{c}\text { Group 1 } \\
\text { Restenosis } \\
(\mathbf{n}=35)\end{array}$ & $\begin{array}{c}\text { Group 2 } \\
\text { Long-Term } \\
\text { Success } \\
\text { (n=54) }\end{array}$ \\
\hline $\begin{array}{l}\text { Weeks after PTCA } \\
\text { (range) }\end{array}$ & $4.7 \pm 2.3(2-11)$ & NS & $4.7 \pm 1.7(2-8)$ \\
$\begin{array}{c}\text { Maximal workload } \\
\text { (\% of predicted) }\end{array}$ & $96 \pm 13$ & NS & $90 \pm 16$ \\
$\begin{array}{l}\text { Maximal heart rate } \\
\text { Abnormal exercise } \\
\text { ECG }\end{array}$ & $140 \pm 28$ & NS & $149 \pm 22$ \\
$\begin{array}{l}\text { Angina during test } \\
\text { ST depression }\end{array}$ & 13 & & 13 \\
$\begin{array}{c}\text { Both } \\
\text { Abnormal }\end{array}$ & 1 & & 3 \\
$\quad \begin{array}{cc}\text { scintigram } \\
\text { Recurrent angina } \\
\text { New myocardial } \\
\text { infarction }\end{array}$ & 11 & & 10 \\
\hline
\end{tabular}

ECG = electrocardiogram; NS = not significant; PTCA = percuta neous transluminal coronary angioplasty.

test on the bicycle ergometer with stepwise increments of 20 W/min. The 3 orthogonal leads XYZ of the Frank lead system were recorded and analyzed as previously described. ${ }^{11}$ The reported sensitivity and specificity for the diagnosis of significant coronary disease were $85 \%$ and $90 \%$, respectively. Horizontal ST depression of $0.1 \mathrm{mV}$ or greater and typical angina during cxercise were considered as abnormal (or positive) responses. One minute before peak exercise, thallium, $1.5 \mathrm{mCi}$, was injected intravenously. Imaging was started 5 minutes later in 3 views: anterior, left anterior oblique $45^{\circ}$ and $65^{\circ}$. Static planar images ( 500 kcounts full field, zoom $2 \times$ ) were obtained after cxercise and 4 hours later with a Searle Phogamma V camera. The scintigraphic images were processed on a DEC gamma-11 system with a quantification procedure developed at our institution. ${ }^{12}$ The late image was corrected for acquisition time differences with respect to the early image. The exercise and redistribution images were registered on the basis of the detected positions of point sources taped to the patient's chest. After automated left ventricular contour detection ${ }^{13}$ and interpolative background correction, ${ }^{14}$ circumferential profiles were computed at $6^{\circ}$ intervals. The profiles of the early and late images were normalized for the maximal value in the early image $(100 \%) \mathrm{ex}$ cluding the outflow tract of the left ventricle. The analog Polaroid ${ }^{(i)}$ images from the gamma camera, the processed images and the circumferential profiles were analyzed prospectively on a routine basis by 3 experienced observers without knowledge of the angiographic data. The thallium uptake in a total of 11 segments was scored both in the postexercise and late images on a 5-point scale: $0=$ no thallium uptake; 1 = severely abnormal; 2 = definitely abnormal; $3=$ doubtfully abnormal; and $4=$ normal. The following segments were defined: posteroseptal, inferior, apical and anterolateral in the anterior view; anteroseptal, apical and posterolateral in the left anterior oblique $45^{\circ}$ view; and anterior, apical, inferior and posterior in the left anterior oblique $65^{\circ}$ view. The scores of all segments were summed per patient and the difference between late and early postexercise sums was taken as a measure of the amount of redistribution. An increase in thallium uptake score of 2 points or more between postexcrcise and late images was taken as the cutoff between normal (absence of exercise-induced ischemia) and abnormal (presence of exercise induced ischemia) scintigrams. Persistent defects without redistribution were considered to represent scars 
TABLE III Positive and Negative Predictive Values of the Noninvasive Tests

\begin{tabular}{|c|c|c|c|c|c|c|}
\hline & \multicolumn{4}{|c|}{ Restenosis } & & \\
\hline & \multicolumn{2}{|c|}{$50 \%$ Diameter } & \multicolumn{2}{|c|}{ NHLBI Criteria* } & \multicolumn{2}{|c|}{ Recurrent Angina } \\
\hline & $\begin{array}{c}\text { Present } \\
(n=35)\end{array}$ & $\begin{array}{c}\text { Absent } \\
(n=54)\end{array}$ & $\begin{array}{l}\text { Present } \\
(n=37)\end{array}$ & $\begin{array}{c}\text { Absent } \\
(n=52)\end{array}$ & $\begin{array}{l}\text { Present } \\
(n=29)\end{array}$ & $\begin{array}{c}\text { Absent } \\
(n=60)\end{array}$ \\
\hline Predictive value & + & - & + & - & + & - \\
\hline ST segment & $\begin{array}{c}55 \\
(12 / 22)\end{array}$ & $\begin{array}{c}66 \\
(44 / 67)\end{array}$ & $\begin{array}{c}55 \\
(12 / 22)\end{array}$ & $\begin{array}{c}63 \\
(42 / 67)\end{array}$ & $\begin{array}{c}32 \\
(7 / 22)\end{array}$ & $\begin{array}{c}67 \\
(45 / 67)\end{array}$ \\
\hline ST and/or AP & $\begin{array}{c}50 \\
(13 / 26)\end{array}$ & $\begin{array}{c}65 \\
(41 / 63)\end{array}$ & $\begin{array}{c}54 \\
(14 / 26)\end{array}$ & $\begin{array}{c}63 \\
(40 / 63)\end{array}$ & $\begin{array}{c}38 \\
(10 / 26)\end{array}$ & $\begin{array}{c}70 \\
(44 / 63)\end{array}$ \\
\hline $\begin{array}{l}\text { Thallium } \\
\text { scintigraphy }\end{array}$ & $\begin{array}{c}74 \\
(26 / 35)\end{array}$ & $\begin{array}{c}83 \\
(45 / 54)\end{array}$ & $\begin{array}{c}74 \\
(26 / 35)\end{array}$ & $\begin{array}{c}80 \\
(43 / 54)\end{array}$ & $\begin{array}{c}66 \\
(23 / 35)\end{array}$ & $\begin{array}{c}89 \\
(48 / 54)\end{array}$ \\
\hline
\end{tabular}

Positive $(t)$ and negative $(-)$ predictive values of respectively abnormal and normal tests are percentages.

- An increase in stenosis of $30 \%$ or more from the immediate post-PTCA result and/or the loss of at least half the initial gain in diameter.

$\mathrm{AP}=$ angina pectoris; $\mathrm{ECG}=$ electrocardiogram; NHLBI = National Heart, Lung, and Blood Institute.

without exercise-induced ischemia. With this analysis, the previously reported sensitivity and specificity for the diagnosis of significant coronary artery obstructions were 80 and $88 \%$, respectively. ${ }^{12}$ The patients were followed up in the outpatient clinic until occurrence of typical angina pectoris or a new myocardial infarction. The follow-up duration was $6.4 \pm 2.5$ months. No patient died during this period.

Results are presented as mean \pm standard deviation. The $t$ test for paired or unpaired data was used whenever appropriate. The positive predictive value for restenosis (or recurrent angina) was calculated as the frequency of restenosis (or recurrent angina) in those with abnormal test results. The negative predictive value for the absence of restenosis (or recurrent angina) was calculated as the frequency of long-term success in those with normal test results. Differences between correct and incorrect classifications by exercise ECG vs thallium were evaluated by the McNemar test.

\section{Results}

The characteristics of the PTCA procedure are listed in Table I for 2 groups: patients with restenosis of the dilated vessel, i.e., diameter stenosis at repeat angiography more than $50 \%(n=35)$, and patients with longterm success $(n=54)$. There was no significant difference between these 2 groups in the pressure gradient across the stenosis either before or after PTCA. The exercise test results and the recurrence of symptoms during the follow-up are summarized for both groups in Table II. The mean timing of exercise testing after PTCA and the resultant maximal workloads and heart rates achieved were similar for both groups. Ninety-two percent of the patients reached $80 \%$ of their predicted maximal workload. An abnormal exercise ECG was observed in 26 patients: 21 had ST-segment depression, 4 had angina at peak workload and 1 patient had both.

Exercise-induced ischemia as assessed by the thallium redistribution was observed in 35 patients. During the follow-up, angina recurred in 29 patients. No patient had a new myocardial infarction in the territory of the dilated vessel. The positive and negative predictive values of each single test are shown in T'able III. 'T'hallium was superior to the exercise ECG both for the prediction of recurrent stenosis and recurrent angina (both $\mathrm{p}<0.005$ ). The predictive value for recurrent stenosis of the 4 combinations of test results is shown in Figure 1. An abnormal scintigraphic response was associated with a high incidence of restenosis, which was not influenced by the result of the exercise ECG: $71 \%$ of restenoses when both tests were abnormal vs $76 \%$ when tests were discordant. Conversely, a normal scintigraphic response was associated with a low incidence of restenosis, which was also not influenced by the result of the exercise ECG: $14 \%$ of restenosis when both tests were normal and $25 \%$ when tests were discordant.

The value of combined noninvasive test results for the prediction of recurrent angina is shown in Figure 2. Angina recurred in $64 \%$ of patients with both tests abnormal and in $67 \%$ of patients with only thallium abnormal. In the presence of a normal scintigraphic response, the recurrent angina was about $10 \%$, regardless of the result of the response on the exercise ECG.

\section{\% RESTENOSIS}

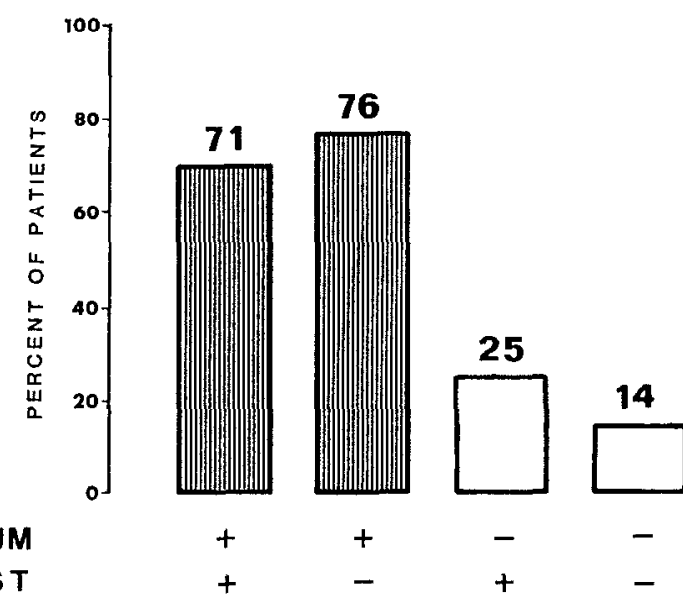

FIGURE 1. The predictive value for angiographic restenosis for the possible combinations of noninvasive test results: $(+)=$ abnormal test and $(-)=$ normal test; EX TEST = exercise electrocardiogram. Shaded columns represent the patients with abnormal scintigraphic responses. Both test results were abnormal in 14 and normal in 42 patients; only thallium was abnormal in 21 and only exercise ECG in 12 patients. 
By the NHLBI definition of restenosis based on the quantitative analysis of the angiograms, only 6 patients were categorized in another group; 37 had restenosis by these critcria. The predictive value of the noninvasive tests was not significantly different: $54 \%$ restenosis when the exercise ECG was abnormal vs $74 \%$ restenosis when the scintigram was abnormal (Table III).

\section{Discussion}

The present report demonstrates that early assessment of myocardial perfusion by exercise thallium scintigraphy has a high predictive value for restenosis and recurrence of angina in patients who underwent a technically satisfactory PTCA. Previous studies $2,6,15-17$ assessing the results of PTCA by noninvasive tests have focused on the reversibility of the ischemic changes after a successful procedure and on their induction at the time of recurrence. However, more recently, DePucy et $\mathrm{al}^{18}$ reported that failure to increase ejection fraction or the development of a new regional wall motion abnormality during exercise radionuclide ventriculography early after PTCA predicted restenosis at 4 to 12 months in $73 \%$ of 41 patients. Their findings and those of the present study suggest that restenosis had occurred to some extent already at 4 weeks in most patients in whom it was documented later. This observation raises speculations about the underlying mechanism of restenosis after dilatation. Fibrocellular proliferations as a reparative response to coronary wall laceration has been described in necropsy studies ${ }^{19}$ and may represent the pathologic substrate of early restenosis. In analogy with aortic dissection, exposure of vascular smooth muscle cells to blood may trigger an exuberant tissue reaction, leading to obliteration of the false channel and eventually of the functional lumen. Preliminary data ${ }^{20}$ from experimental angioplasty in pigs suggest that balloon dilatation is a potent stimulus

\section{\% RECURRENCE OF ANGINA}

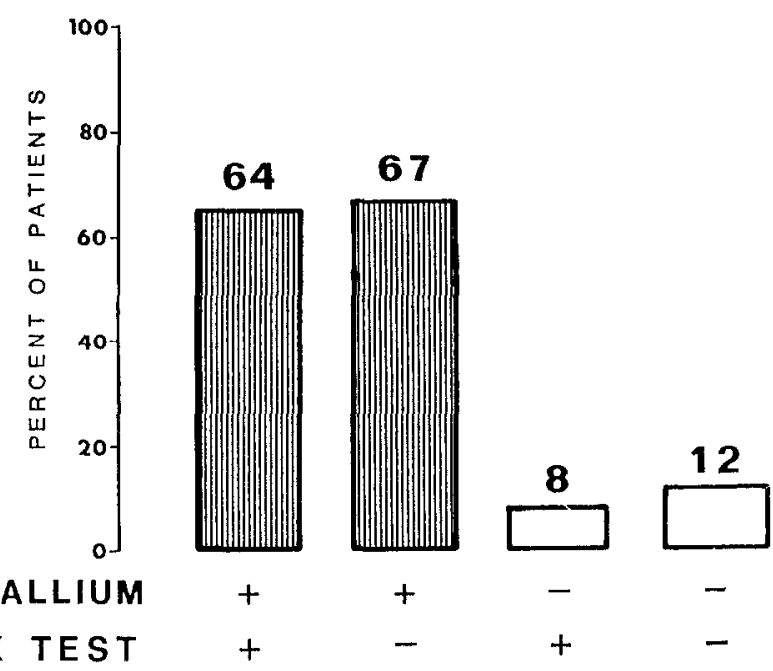

FIGURE 2. The predictive value of the noninvasive tosts for the clinical endpoint (recurrent angina); other abbreviations as in Figure 1. to early platelet deposition and subsequent intimal hyperplasia. In this model, the reparative process was observed as early as 2 weeks after the procedure. If present in patients, such ongoing processes may have induced the observed perfusion abnormalities. Since only successful cases were included and the decrease in stenosis severity and in the transstenotic pressure gradient were comparable in patients with restenosis and long-term success, there is no evidence that recurrence occurred predominantly in patients in whom the dilatation was incomplete. In this study, the high predictive value of the perfusion scintigram contrasts with the poor predictive value of the exercise electrocardiographic response, especially for the prediction of restenosis.

This could be explained by a lower sensitivity of the exercise ECG compared with thallium scintigraphy in the detection of moderate coronary artery narrowing. The combination of a normal exercise ECG with a reversible thallium perfusion abnormality could be an early indicator of the presence of a noncritical stenosis, still insufficient to induce ST-segment depression during exercise. ${ }^{21}$ Indeed, $66 \%$ of the patients with an initially abnormal scintigram became symptomatic at a later stage during the follow-up period.

The problem of defining restenosis is not trivial. Applying the stringent criteria of the NHLBI registry to visual estimations of stenosis severity has major limitations, due to the large intra- and interobserver differences in interpretation, especially for stenoses between 20 and $80 \% .{ }^{22}$ Therefore, the stenoses were analyzed by computerized edge detection. Although this method may not be optimal after angioplasty, ${ }^{9}$ it provides an objective and quantitative measurement, avoiding unintentional bias in reading the angiograms. This complex definition of restenosis resulted however in similar findings as the usual clinical approach based in the presence or the absence of a hemodynamically significant stenosis ( $>50 \%$ luminal diameter). By this clinical definition, restenosis of the dilated artery was observed in 39\% and recurrent angina pectoris in 33\% of the patients.

The true incidence of recurrence is probably lower because most of the patients who refused to undergo repeat angiography were asymptomatic. The patient population is thus biased in favor of those with recurrent stenosis. The clinical implication of these findings for the routine management of patients who undergo PTCA remains to be established. Certainly we share with DePuey et al ${ }^{18}$ the conclusion that an abnormal noninvasive test early after PTCA in an asymptomatic patient is an indication for close clinical monitoring in view of the high chance of recurrence of symptoms. We believe that decisions to perform repeat angiography, followed by a redilatation when restenosis is found, should primarily be based on the severity of angina rather than on the results of the testing procedure. This is analogous to the issue of bypass surgery for documented coronary artery disease in asymptomatic patients, particularly since no benefit of surgical intervention over pharmacologic treatment was shown in mildly or nonsymptomatic patients. ${ }^{23}$ Until the outcome 
of prophylactic PTCA is studied, the procedural complications and incomplete success rates militale against performing PTCA when diagnostic testing reveals restenosis in the absence of symptoms.

Acknowledgment: We acknowledge G. Koster for expert preparation of the manuscript. We are especially grateful to P. van Eldik and J.W. Deckers, MD, for analyzing the coronary angiograms.

\section{References}

1. Gruentzig AR, Senning A, Siegenthaler WE. Nonoperative dilatation of coronary artery stenosis: percutaneous transluminal angioplasty. N Engl $\mathrm{J}$ Med 1979;301:61-68.

2. Scholl JM, Chaitman BR, David PR, Dupras G, Brevers G, Val PG, Crepeau J, Lesperance J, Bourassa MG. Exercise electrocardiography and myocardial scintigraphy in the serial evaluation of the results of percutaneous transluminal coronary angioplasty. Circulation 1982;66:380-389.

3. Kaltenbach $M$, Scherer D, Kober G. Longterm results of coronary angioplasty. (abstr) Circulation 1983;68:suppl Ill: Ill-95.

4. Holmes DR Jr, Vlietstra RE, Smith HC, Vetrovec GW, Kent KM, Cowley MJ, Faxon DP, Gruentzig AR, Kelsey SF, Detre KM, van Raden MJ, Mock MB. Restenosis after percutaneous transluminal coronary angioplasty (PTCA): a report from the PTCA registry of the National Heart, Lung, and (PTCA): a report from the PTCA registry of the Natic
Blood Instltute. Am J Cardiol $1984 ; 53: 77 \mathrm{C}-81 \mathrm{C}$.

5. Thornton MA, Gruentzig AR, Hollman J, King SB, Douglas JS. Coumadin and aspirin in prevention of recurrence after transluminal coronary angioplasty: a randomized study. Girculation 1984;69:721-727.

6. Hirzel HO, Neusch $K$, Gruentzig AR, Zuetoll VM. Short- and long-term changes in myocardial perfusion after percutaneous transluminal coronary angioplasty assessed by thallium-201 exercise scintigraphy. Circulation 1981;63:1001 1007.

7. Serruys PW, van den Brand M, Brower RW, Hugenholtz PG. Regional cardioplegia and cardioprotection during transluminal angioplasty, which role for niledipine? Eur Heart J 1983;4: 115-121.

8. Serruys $P W$, Wijns $W$, van den Brand $M$, Ribeiro $V$, Fioretti $P$, Simoons ML, Kooyman CJ, Reiber JHC, Hugenholtz PG. Is transluminal coronary angioplasty mandatory after successful thrombolysis? Br Heart J 1983; 50:257-265

9. Serruys PW, Reiber JHC, Wijns W, Kooijman CJ, van den Brand M, ten Katen $\mathbf{H J}$, Hugenholtz PG. Assessment of PTCA by quantitative coronary angiography: diameter vs densitometric area measurements. Am J Cardiol
1984;54:482-488

10. Reiber JHC, Serruys PW, Kooijman CJ, Wijns W, Slager C.J, Gerbrands JJ, Schuurbiers JCH, den Boer A, Hugenholtz PG. Assessment of short-, medium- and long-term variations in arterial dimensions from computerassisted quantitation of coronary angiograms. Circulation 1985, in press.

11. Simoons ML, Hugenholtz PG. Estimation of the probability of exerciseinduced ischemia by quantitative ECG analysis. Girculation 1977;56: $552-559$.

12. Reiber JHC, Lie SP, Simoons ML, Wijns W, Gerbrands JJ. Computer quantification of location, extent and type of thallium-201 myocardial perfusion abnormalities. In: Proc Int Symposium on Medical Imaging and Image Interpretation ISMIII. Institute of Flectrical and Electronics Engineers 1982; Cat. No. $82 \mathrm{CH} 1804-4: 123-128$.

13. Lie SP, Reiber JHC, Simoons ML, Gerbrands JJ, Kooy PPM, Bakker WH. Computer processing of thallium-201 myocardial scintigrams. In- Proc 2nd Int Gonf Visual Psychophysics and Medical Imaging. IEEE 1981 Cat. No. 81 CH 1676-6:19-25.

14. Watson DD, Beller GA, Berger BC, Teates CD. Notes on the quantitation of sequential thallium-201 images. Softwhere 1979;6:4-10.

15. Kent KM, Bonow RD, Rosing DR, Ewels C.J, Lipson LC, Mcintosh CL, Bacharah S, Green M, Epstein SE. Improved myocardial function during exercise after successful percutaneous transluminal coronary angioplasty. N Engl J Med 1982;306:441-445.

16. Kanemoto N, Hor G, Kober G, Maul FD, Klapzig H, Standkerk, Kaltenbach $M$. Noninvasive assessment of left ventricular performance following transluminal coronary angioplasty. Int J Cardiol 1983;3:281-292.

17. Rosing DR, van Raden MJ, Mincemoyer RM, Bonow RD, Bourassa MG, David PR, Ewels CJ, Detre KM, Kent KM. Exercise, electrocardiographic and functional responses after percutaneous transluminal coronary anand functional responses after percutaneou

18. DePuey EG, Leatherman LL, Leachmand RD, Dear WE, Massin EK, Mathur VS, Burdine JA. Detection of restenosis following transluminal coronary angioplasty with exercise gated radionuclide ventriculography. JACC 1985 , in press.

19. Essed CE, van den Brand M, Becker AE. Transluminal coronary angioplasty and early restenosis: Fibrocellular occlusion after wall laceration. $\mathrm{Br}$ Heart J 1983;49:393-396.

20. Steele PM, Chesebro JH, Lamb HB, Stanson AW, Badimon L, Fuster V. Natural history of balloon angioplasty in pigs: Wall injury platelet-thrombus deposition and intimal hyperplasia (abstr). Circulation 1983;68:suppl III: III-264.

21. Pohost GM, Alpert NM, Ingwall JS, Strauss HW. Thallium redistribution: mechanism and clinical utility. Semin Nucl Med 1980;10:70-93.

22. Shub C, Vlietstra RE, Smith HC, Fulton RE, Elveback LR. The unpredictable progression of symptomatic coronary artery disease, a serial clinicalangiographic analysis. Mayo Clin Proc 1981;56:155-160.

23. CASS Principal Investigators and Their Associates. Coronary artery bypass surgery. Circulation 1983;68:939-950. 